\title{
Quantitation of endogenous levels of IAA, IAAsp and IBA in micro-propagated shoots of hybrid chestnut pre-treated with IBA
}

\author{
José Carlos Gonçalves • Graça Diogo • \\ Maria Teresa Coelho • Nieves Vidal • Sara Amâncio
}

Received: 29 January 2008 / Accepted: 20 August 2008 / Published online: 24 September 2008 / Editor: P. Druart

(C) The Society for In Vitro Biology 2008

\begin{abstract}
Endogenous levels of indole-3-acetic acid (IAA), indole-3-acetylaspartic acid (IAAsp) and indole-3-butyric acid (IBA) were measured during the first $8 \mathrm{~d}$ of in vitro rooting of rootstock from the chestnut 'M3' hybrid by high performance liquid chromatography (HPLC). Rooting was induced either by dipping the basal ends of the shoots into a 4.92-mM IBA solution for $1 \mathrm{~min}$ or by sub-culturing the shoots on solid rooting medium supplemented with 14.8$\mu \mathrm{M}$ IBA for $5 \mathrm{~d}$. For root development, the induced shoots were transferred to auxin-free solid medium. Auxins were measured in the apical and basal parts of the shoots by means of HPLC. Endogenous levels of IAA and IAAsp were found to be greater in IBA-treated shoots than in control shoots. In extracts of the basal parts of the shoots, the concentration of free IAA showed a significant peak $2 \mathrm{~d}$ after either root inductive method and a subsequent gradual decrease for the remainder of the time course. The concentration of IAAsp peaked at day 6 in extracts of the basal parts of shoots induced with $14.8-\mu \mathrm{M}$ IBA for $5 \mathrm{~d}$, whereas shoots induced by dipping showed an initial increase until day 2 and then remained stable. In extracts from basal shoot portions induced by dipping, IBA concentration showed a transient peak at day 1 and a
\end{abstract}

J. C. Gonçalves $(\bowtie) \cdot$ G. Diogo • M. T. Coelho

Escola Superior Agrária,

Qta Sra de Mércules, 6001-909 Castelo Branco, Portugal

e-mail: jcgoncalves@esa.ipcb.pt

N. Vidal

Instituto de Investigaciones Agrobiológicas de Galicia (CSIC),

Ap. 122, 15080 Santiago de Compostela, Spain

S. Amâncio

DBEB/CBAA, Instituto Superior de Agronomia, UTL,

1349-017 Lisboa, Portugal plateau between day 2 and 4, in contrast to the profile of shoots induced on auxin-containing medium, which showed a significant reduction between 4 and $6 \mathrm{~d}$ after transferred to auxin-free medium. All quantified auxins remained at a relatively low level, virtually constant, in extracts from apical shoot portions, as well as in extracts from control non-rooting shoots. In conclusion, the natural auxin IAA is the signal responsible for root induction, although it is driven by exogenous IBA independently of the adding conditions.

Keywords Auxins · Chestnut Adventitious root formation

\section{Introduction}

The formation of adventitious roots depends upon a complex interaction between endogenous and environmental factors. While exogenously applied auxins are recognised as rooting stimulators (Eliasson and Arebald 1984; Nordström and Eliasson 1991; Riov 1993), the role of endogenous auxin in rhizogenesis and their signaling is complex and is still far from being fully understood (Moncousin 1991; Blakesley 1994; Woodward and Bartel 2005; Vieten et al. 2007). The uptake and metabolism of applied auxins may affect rooting ability and the subsequent development of adventitious roots (Baraldi et al. 1995), with the interdependent physiological phases of the rooting process being associated with changes in endogenous auxin concentrations (Moncousin et al. 1988; Hausman 1993). Blakesley (1994) and Gaspar et al. (1994) postulated that an early and transient increase of endogenous free auxin concentration occurs during the inductive phase of rooting. Furthermore, Jarvis (1986) has proposed that an accumulation of indole-3-acetic acid 
(IAA) in the root-forming part of the cutting will function as the triggering factor for root initiation, whereas the later stage of primordia development is believed to be favored by lowered auxin content. Heloir et al. (1996) and Gatineau et al. (1997) reported that the IAA content during rooting of in vitro-propagated walnut shoots peaked at $36 \mathrm{~h}$ and then exhibited a relatively low concentration for the remainder of the rooting phase. The fall in free IAA can be attributed to conjugation or to oxidative catabolism, which are important mechanisms in the regulation of free IAA levels in plant tissue (Bandurski 1980; Hand 1994). In fact, this conjugation also prevents the over-accumulation of IAA in tissues, which is a common occurrence after exogenous auxin application (Faivre-Rampant et al. 2002). Recently, Stenfancic et al. (2007) reported that the highest free and conjugated IAA accumulations in leafy bases of cherry rootstock 'GiSelA 5' cuttings are observed after pretreatment with IAA in comparison to indole-3-butyric acid (IBA), without promoting the percentage of rooted cuttings.

In the case of chestnut cultured in vitro, the promotion of root formation is IBA-dependent (Vieitez et al. 1986; Gonçalves et al. 1998). The sequential anatomical changes during the rooting process reveal that the first cellular divisions occur in some of the cambial derivative cells $24 \mathrm{~h}$ after auxin induction and that meristemoids became individualised after 3-4 d, with the root primordia defined by $6-8 \mathrm{~d}$, and roots with organised tissue systems emerging from the stem 10-12 d after application of the root induction treatment (Gonçalves et al. 1998). The goal of the present work was to monitor the concentration of endogenous IAA, one of its metabolites, IAA-aspartic acid, and of the applied IBA in micro-propagated shoots of hybrid chestnut rootstock 'M3' during the first $8 \mathrm{~d}$ after IBA treatment.

\section{Materials and Methods}

Plant material and culture conditions. Stock shoot multiplication cultures of a hybrid adult clone of chestnut (Castanea sativa $\times$ Castanea crenata), clone 'M3', were multiplied as previously described (Gonçalves et al. 1998). Axillary shoots, $3-4 \mathrm{~cm}$ in length with two-four leaves each, were selected for in vitro rooting. For root induction, the basal part of the micro-shoots were either dipped for $1 \mathrm{~min}$ in a $15 \% \mathrm{v} / \mathrm{v}$ hydro-alcoholic solution containing $4.92 \mathrm{mM}$ IBA or placed for $5 \mathrm{~d}$ on a $14.7-\mu \mathrm{M}$ IBA basal medium (Fig. 1) and then transferred to auxin-free medium of the same type. These two methods allow $97 \%$ and $93 \%$ of the micro-shoots to root, respectively (Gonçalves et al. 1998). For induction and root expression, the basal medium was Murashige and Skoog (Murashige and Skoog 1962) with macro-nutrients at half strength, with the exception of nitrates, which were reduced to quarter strength. The medium was supplemented with $3 \% w / v$ sucrose, adjusted to $\mathrm{pH} 5.7$ and solidified with $0.7 \% w / v$ Difco Bacto agar. During the rooting process, the shoots were cultured in a growth chamber at a day/night temperature of $25^{\circ} \mathrm{C} / 20^{\circ} \mathrm{C}$ with a 16-h photoperiod and a light intensity of $45 \pm 5 \mu \mathrm{mol}$ $\mathrm{m}^{-2} \mathrm{~s}^{-1}$ provided by cool-white fluorescent lamps. With this protocol, almost $100 \%$ rooting of the isolated shoots was achieved with both induction methods (Gonçalves et al. 1998) (Fig. 2). Non-rooting shoots cultured on basal rooting medium in the absence of IBA were used as controls.

Extraction and quantification of auxins. Apical and basal parts of equal length $(1.5$ to $2.0 \mathrm{~cm})$ of the shoots, separately and without leaves, were used for the extraction and analysis of auxins. The shoots were collected daily until day 8 , immediately frozen in liquid nitrogen and stored at $-86^{\circ} \mathrm{C}$. The samples were freeze-dried and the lyophilised powder extracted with the method described by Nordström and Eliasson (1991) and Nordström et al. (1991). Briefly, $100 \mathrm{mg}$ of the lyophilised powder of each part of the shoots was homogenised in $15 \mathrm{ml}$ of $5 \mathrm{mM} \mathrm{K}$ phosphate buffer, $\mathrm{pH}$ 6.5, containing butylated hydroxytoluene as antioxidant and naphthaleneacetic acid as internal standard. After $1 \mathrm{~h}$ in darkness, the extract was filtered through a glass-fibre filter which was then rinsed with $5 \mathrm{ml}$ of the extraction buffer and divided into two $10 \mathrm{ml}$ portions. Each portion was first run through a Chromabond C18 column, $100 \mathrm{mg}$, activated with $2 \mathrm{ml}$ of ethanol and conditioned with $2 \mathrm{ml}$ of double distilled water and extraction buffer at $\mathrm{pH} 6.5$ and then washed with $5 \mathrm{ml}$ of $5 \mathrm{mM}$ K-phosphate buffer, $\mathrm{pH}$ 6.5. The eluate, containing the putative IAA, indole-3-acetylaspartic acid (IAAsp) and IBA, was acidified to $\mathrm{pH} 2.5$ with $2.5 \mathrm{M}$ phosphoric acid and applied to two $\mathrm{C} 18$ columns activated and conditioned to $\mathrm{pH} 2.5$. The columns were washed with $2 \mathrm{ml}$ distilled water, $2 \mathrm{ml}$ acidic ethanol (ethanol to acetic acid to water, 20:2:78 v:v) and again with $2 \mathrm{ml}$ distilled water. As the acidic ethanol fraction contained a greater part of the IAAsp as it was recovered, the solvents were evaporated in a Speed-Vac system at $30^{\circ} \mathrm{C}$ and the residue dissolved in $1.2 \mathrm{ml} \mathrm{80 \%} \mathrm{methanol.} \mathrm{Auxins} \mathrm{were} \mathrm{eluted} \mathrm{from} \mathrm{each} \mathrm{of} \mathrm{the}$ two $\mathrm{C} 18$ columns ( $\mathrm{pH} 2.5$ ) with a $100-\mu$ l aliquot of $100 \%$ methanol and a $500-\mu l$ aliquot of $80 \%$ methanol.

The combined methanol extracts $(1.2 \mathrm{ml})$ were filtered through a $0.22-\mu \mathrm{m}$ nylon filter, and $30 \mu \mathrm{l}$ of each sample was injected into a Waters HPLC, model 590, with a Waters 470 fluorescence detector (excitation $292 \mathrm{\eta m}$, emission $360 \mathrm{\eta m}$ ), and a fully automated injection Waters 717 plus Autosampler system. The high performance liquid chromatography (HPLC) column used was a Hypersil ODS, $6 \mathrm{~cm}$ 
Figure 1. Root induction treatments. (A) Shoots treated by culture for $5 \mathrm{~d}$ in agar medium supplemented with $14.7 \mu \mathrm{M}$ IBA. (B) Shoots treated by dipping in $4.92 \mathrm{mM}$ IBA solution for $1 \mathrm{~min}$. The bar represents $1 \mathrm{~cm}$.

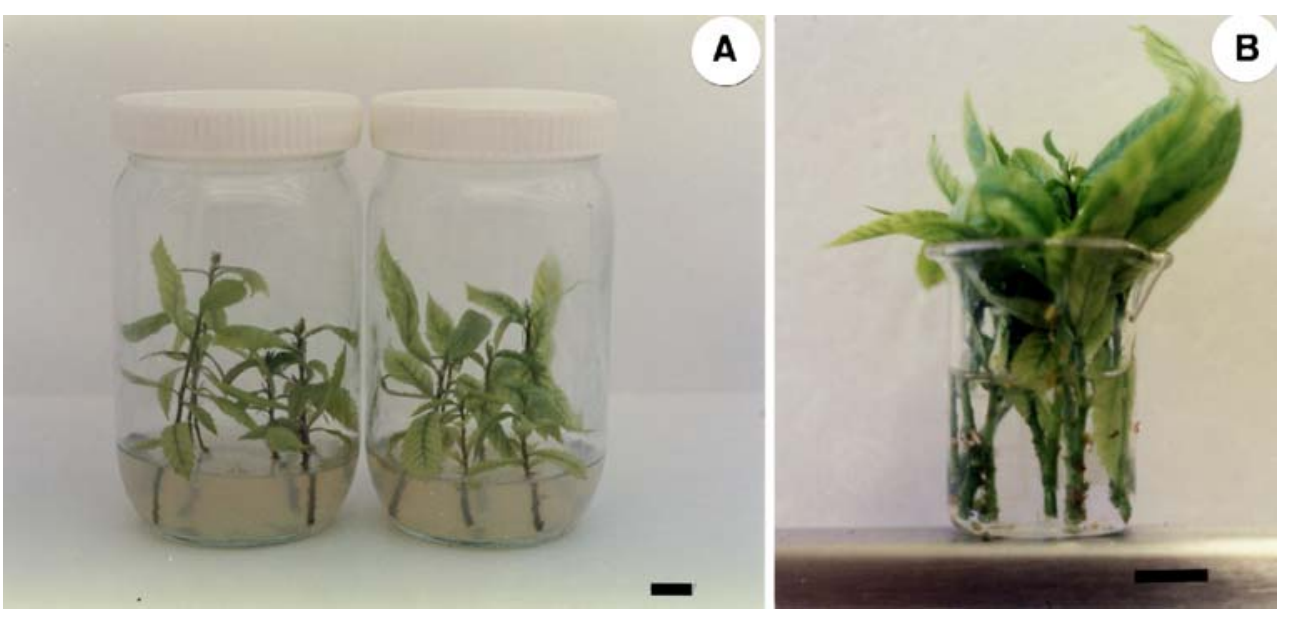

long, $3 \mu \mathrm{m}$ particle size, solvent and column at $20^{\circ} \mathrm{C}$, flow rate $1 \mathrm{ml} \mathrm{min}^{-1}$. The mobile phase was $84 \%$ acetonitrile/ glacial acetic acid/water $(10 / 2 / 88, v / v)$ and $16 \%$ acetonitrile for the IAA and IBA fraction and $95 \%$ and $5 \%$, respectively, for the IAAsp fraction. The system was operated isocratically. Under these experimental conditions, IAAsp eluted after $1.68 \mathrm{~min}$, IAA after $3.38 \mathrm{~min}$ and IBA after $9.55 \mathrm{~min}$. Auxins were quantified by computing the peak area using Millennium ${ }^{\mathrm{TM}}$ Chromatography Manager 2010 software. Fractions were collected and analysed

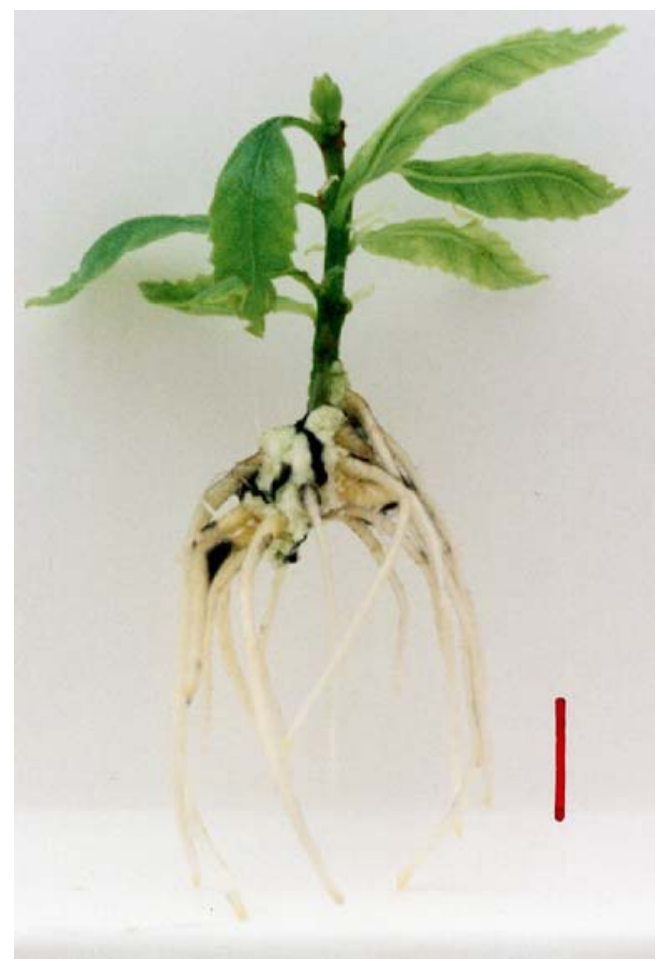

Figure 2. Rooted shoot after $4 \mathrm{wk}$ of root induction. The bar represents $1 \mathrm{~cm}$. through Gas chromatography-mass spectrometry (GCMS), to confirm the identity of IAA.

Experimental design and statistical methods. Each sample (100 mg of lyophilised powder) was prepared from 24 shoots divided into basal parts and apical parts (approximately $15 \mathrm{~mm}$ each). Each treatment was performed in triplicate and the extracts were also analysed in duplicate. Each point is the mean of six values associated with the standard error and was expressed by $\eta$ mol $\mathrm{g}^{-1}$ dry weight (dw).

\section{Results and Discussion}

Auxin analysis by GC/MS and LC/MS techniques can determine concentrations at picogram levels, reducing significantly the required sample size (Edlund et al. 1995). The results obtained by HPLC with a fluorescence detector in comparative studies with in vitro woody species were sufficiently accurate to draw consistent conclusions (Moncousin et al. 1988; Heloir et al. 1996; Gatineau et al. 1997; Stefancic et al. 2007). In the present work, the concentration of endogenous IAA, IAAsp and IBA within tissues of basal and upper parts of in vitro propagated chestnut shoots were analysed by HPLC during the first $8 \mathrm{~d}$ after two root inducing treatments, either dipping in IBA solution or after culture in IBA-containing agar solidified medium. The internal IAA concentration in the treated shoot bases was found to increase significantly during the first $2 \mathrm{~d}$, up to a transient peak and decreased thereafter. However, by day 8 , the values were significantly higher than in control shoots such that $13.64 \eta \mathrm{mol} \mathrm{g}{ }^{-1} \mathrm{dw}$ was detectable within shoots treated by the dipping method, and $6.18 \mathrm{\eta mol} \mathrm{g}^{-1} \mathrm{dw}$ for shoots cultured with IBA in semi-solid medium, compared to $0.82 \eta \mathrm{mol} \mathrm{g}^{-1} \mathrm{dw}$ for non-treated control shoots 
(Fig. $3 A$ ). In the apical parts of the IBA-dipped shoots (Fig. $3 B$ ), the maximum concentration of IAA remained lower than that of the basal end, with a content of $7.1 \eta \mathrm{mol}$ $\mathrm{g}^{-1} \mathrm{dw}$ observed on day 1 , which is one fifth the value achieved within the basal shoot parts at day 2 (Fig. $3 A$ ). An increase in the concentration of free IAA during the first 24-48 h had also been observed during rooting of vine cuttings (Moncousin et al. 1988), wild cherry (Label et al. 1989), walnut after IBA treatment (Heloir et al. 1996; Gatineau et al. 1997) and in cherry rootstock 'GiSelA 5' leafy cuttings pre-treated with IAA and IBA (Stefancic et al. 2007). This increasing IAA concentration in chestnut seems to be an important step towards achieving the effective induction phase of rooting with corresponding meristemoid differentiation which occurs between days 3 and 4 (Gonçalves et al. 1998) and appears to be a common physiological pattern during the induction phase (Nag et al. 2001; Faivre-Rampant et al. 2002). Subsequent decreases in IAA levels should enable the evolution of the meristemoids into root primordia, which occurs between days 6 and 8 (Gonçalves et al. 1998). These variations in the concentration of endogenous IAA correspond to an inverse variation in IAAsp concentration (Fig. $4 B$ ) and in peroxidase activity of an equivalent chestnut system (Gonçalves et al. 1998), oak (San-José et al. 1992), walnut (Ripetti et al. 1994) and vine (Gaspar et al. 1994).

Over the 8-d culture period, the endogenous free IAA level in non-rooting control shoots remained constantly at very low concentrations, both within the basal and apical regions of the shoots cuttings (Fig. $3 A, B$ ). In addition, the IAAsp concentration also remained constant in these tissues (Fig. $4 A, B$ ). However, in IBA-treated shoots, the IAAsp concentration increased significantly, especially in those cultured with IBA in the rooting medium (Fig. 4A) and reached a peak at day 6 . In the dipping method, the IAAsp level increased to day 1 and then remain stable. This may indicate that conversion to IAAsp could be the predominant metabolic route for regulation of the IAA content. Heloir et al. (1996) reported that the IAAsp concentration in the basal portions of rooting walnut shoots peaked about $36 \mathrm{~h}$ earlier than the free IAA (12 h versus $48 \mathrm{~h})$. Stenfancic et al. (2007) detected the highest basal IAAsp concentration after the first experimental day, simultaneous to the highest free IAA, as observed in our experiment with the dipping method. These differences may be due to genetic characteristics or may reflect differences in the time of IAA conjugation. The potential role of IAA conjugates in the control of adventitious root initiation has been discussed by several authors (Nordström and Eliasson 1991; Blakesley 1994). Nevertheless, IAAsp applied to the rooting solution did not stimulate rooting (Nordström et al. 1991), which supports the assumption that once endogenous IAA is conjugated to IAAsp, it does not stimulate adventitious root initiation.

In basal portions of the dip-treated shoots, the IBA levels peaked pronouncedly at day 1 , decreased through to day 4 and remained stable thereafter. This pattern anticipates the IAA pattern, which peaks at day 2, decreases to day 3 and stabilises thereafter (Fig. 5A). Shoots induced with IBA in the medium maintained high levels until day 4 , then a marked decrease was observed between days 4 and 6 , after the shoots were transferred to an IBA-free medium. It is worth noting that IAA of equivalent samples peaked at day 2 and then decreased sharply. Once again, the apical portions of the shoots showed significantly lower concentrations when compared to the basal portions (Fig. 5B). As expected, in the control shoots, the IBA concentration remained low throughout the experiment (Fig. $5 A, B$ ).

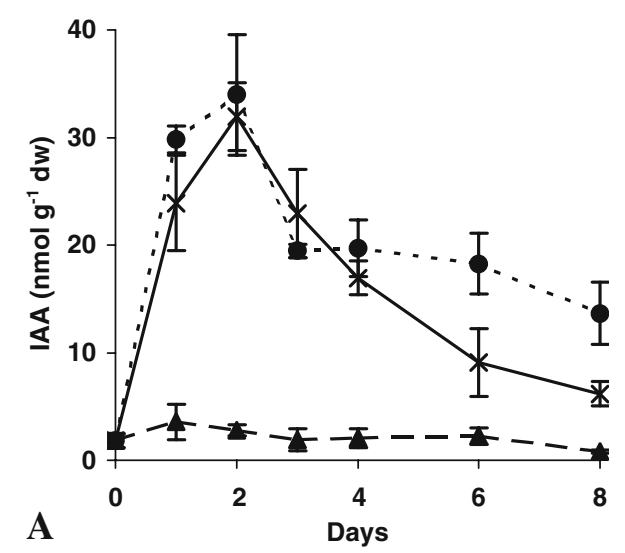

Figure 3. IAA content in micro-shoots of hybrid chestnut rootstock 'M3' treated with IBA, during the first $8 \mathrm{~d}$ of root formation. (A) Basal parts of the shoots. $(B)$ Apical parts of the shoots. (filled triangle) Control; (filled circle) shoots treated by dipping in $4.92 \mathrm{mM}$ IBA

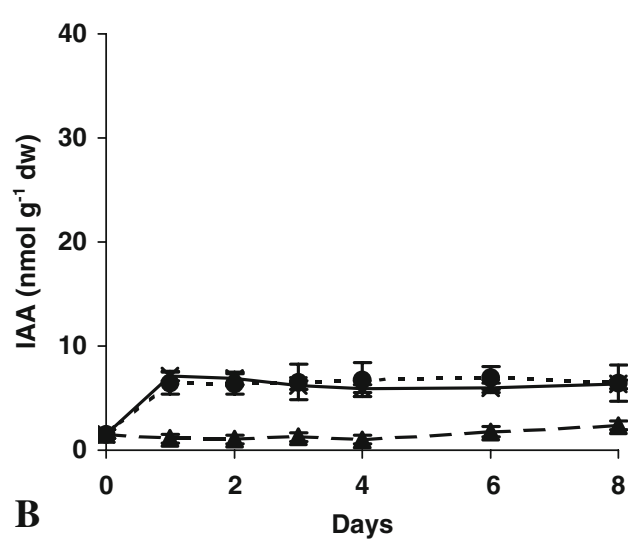

solution for $1 \mathrm{~min} ;(\times)$ shoots treated by culture for $5 \mathrm{~d}$ in agar medium supplemented with $14.7 \mu \mathrm{M}$ IBA. Means of three replicates from three separate experiments $\pm \mathrm{SE}$ (within symbols if not visible) are shown. 


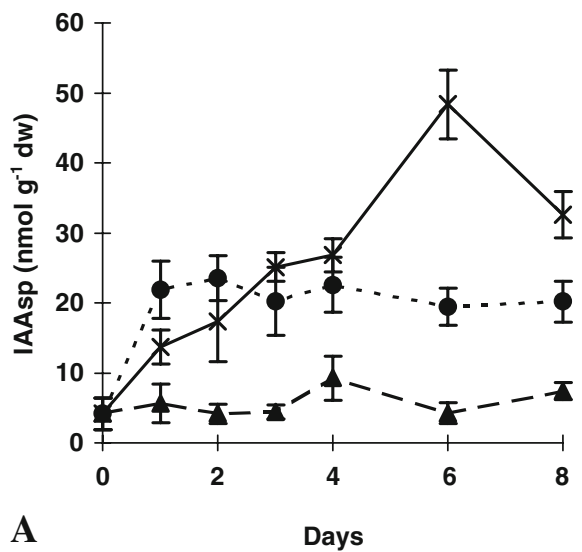

Figure 4. IAAsp content in micro-shoots of hybrid chestnut rootstock 'M3' treated with IBA, during the first $8 \mathrm{~d}$ of root formation. (A) Basal parts of the shoots. $(B)$ Apical parts of the shoots. (filled triangle) Control; (filled circle) shoots treated by dipping in $4.92 \mathrm{mM}$ IBA

The hormonal quantification presented in this work shows that the application of exogenous IBA led to an accumulation IAA in the basal parts of the shoots, where rhizogenesis occurred. The promotive effect of IBA on root neoformation could be explained either as an effect the IBA itself or by an influence on internal IAA concentrations. The first statement was reported by Nordström et al. (1991) during adventitious root formation in pea cuttings, and the second was suggested by Dunberg et al. (1981) in Pinus sylvestris and Epstein and Lavee (1984) in grapevine and olive, respectively. The increase in IAA concentration during the first $48 \mathrm{~h}$ may be due to a fast transformation of IBA into IAA, as has been reported by other authors in other species (Epstein and Lavee 1984; van der Krieken et al. 1992; Epstein and Ludwig-Müller 1993; Stenfancic et al. 2007) rather than from the hydrolysis of auxin conjugates (Bandurski 1980), since, in the same period, the IAAsp

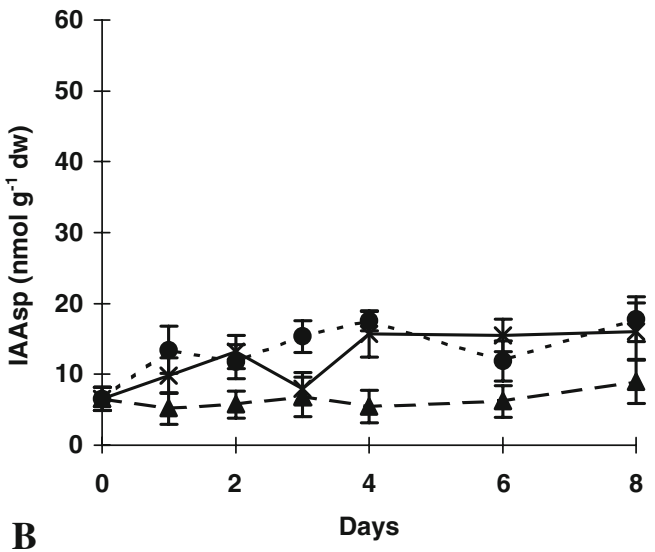

solution for $1 \mathrm{~min}$; $(\times)$ shoots treated by culture for $5 \mathrm{~d}$ in agar medium supplemented with $14.7 \mu \mathrm{M}$ IBA. Means of three replicates from three separate experiments $\pm \mathrm{SE}$ (within symbols if not visible) are shown.

concentration showed a gradual increase (Fig. 4A). However, this remains to be confirmed by the use of labelled compounds. The subsequent decrease of IAA, after day 2, is possibly due to the transformation of free IAA into conjugated IAAsp or other compounds, since it is well known that plant tissues contained most of their IAA as derivatives, either esterified or as peptide conjugated (Bandurski and Schulze 1997; Domagalski et al. 1987). A second reason for this IAA decrease is its oxidation by IAA oxidase, which might contribute to the regulation of the IAA gradient through IAA catabolism and thus help regulate cellular expansion (Vatulescu et al. 2004).

In the present study, after the application of the two root inducing methods, the early pattern of endogenous free IAA concentration within tissues of chestnut micro-shoot cuttings was almost equivalent, irrespective of temporal variations in endogenous IAAsp and IBA. This effect can

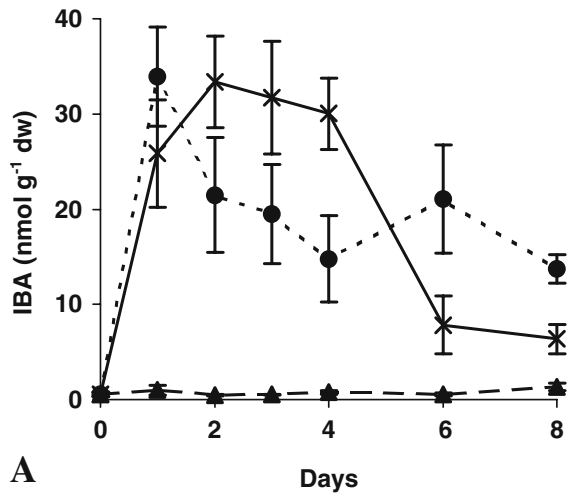

Figure 5. IBA content in micro-shoots of hybrid chestnut rootstock 'M3' treated with IBA, during the first $8 \mathrm{~d}$ of root formation. (A) Basal parts of the shoots. $(B)$ Apical parts of the shoots. (filled triangle) Control; (filled circle) shoots treated by dipping in $4.92 \mathrm{mM}$ IBA

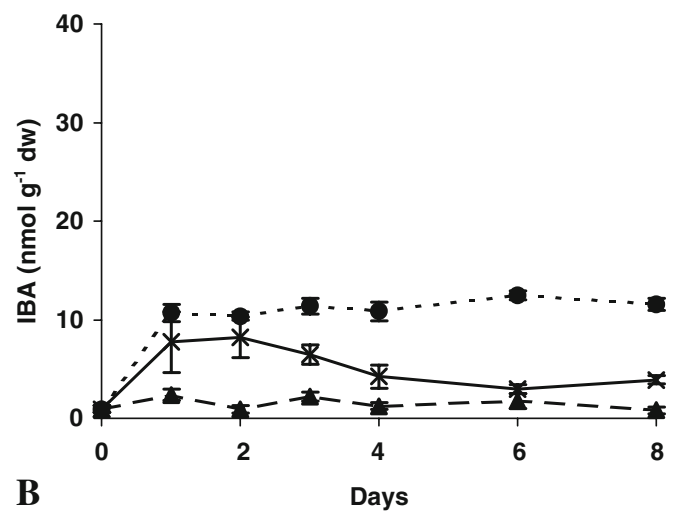

solution for $1 \mathrm{~min} ;(\times)$ shoots treated by culture for $5 \mathrm{~d}$ in agar medium supplemented with $14.7 \mu \mathrm{M}$ IBA. Means of three replicates from three separate experiments $\pm \mathrm{SE}$ (within symbols if not visible) are shown. 
explain similar results obtained on rooting performance as reported in a previous work (Gonçalves et al. 1998) and it allows us to draw the conclusion that accumulation of free IAA is driven by exogenous IBA, irrespective of the method of application, with the former being the signal responsible for root induction.

Acknowledgements Thanks are given to Dr. A. Ballester for his comments upon critical reading of the manuscript. The technical assistance of Conceição Vitorino and Raquel Sabel is gratefully acknowledged. This research was partially supported by FCT under CBAA and CERNAS Plurianual Program.

\section{References}

Bandurski R. S. Homeostatic control of concentrations of indole-3acetic acid. In: Skoog F. (ed) Plant growth substances. Springer, Berlin, pp 37-49; 1980.

Bandurski R. S.; Schulze A. Concentration of indole-3-acetic acid and its derivatives in plants. Plant Physiol. 60: 211-213; 1997.

Baraldi P.; Bertazza G.; Bregoli A. M.; Fasolo F.; Rotondi A.; Predieri S.; Serafini-Fracassini D.; Slovin J. P.; Cohen J. D. Auxins and polyamines in relation to differential in vitro rooting on microcuttings of two pear cultivars. J Plant Growth Regul. 14: 49-59; 1995. doi:10.1007/BF00212646.

Blakesley D. Auxin metabolism and adventitious root initiation. In: Davies, T. D.; Haissig B. E. eds. Biology of adventitious root formation. Plenum, New York, pp 143-154; 1994.

Domagalski W.; Schulze A.; Bandurski R. S. Isolation and characterisation of esters of indole-3-acetic acid from the liquid endosperm o the horse chestnut (Aesculus species). Plant Physiol. 84: 1107-1113; 1987.

Dunberg A.; Hsihan S.; Sandberg G. Auxin dynamics and the rooting of cuttings of Pinus sylvestris. Plant Physiol. 67: S-5; 1981 (Abstr no. 19).

Edlund A.; Eklof S.; Sundberg B.; Moritz T.; Sandberg G. A. A microscale technique for gas chromatography-mass spectrometry measurements of pictogram amounts of indole-3-acetic acid in plant tissues. Plant Physiol. 108: 1043-1047; 1995.

Eliasson L.; Arebald K. Auxin effects on rooting of pea cuttings. Physiol Plant. 61: 293-297; 1984. doi:doi:10.1111/j.1399-3054. 1984.tb05911.x.

Epstein E.; Lavee S. Conversion of indole-3-butyric acid to indole-3acetic acid by cuttings of grapevine (Vitis vinifera) and olive (Olea europea). Plant Cell Physiol. 25: 697-703; 1984.

Epstein E.; Ludwig-Müller J. Indole-3-butyric acid in plants: occurrence, synthesis, metabolism and transport. Physiol Plant. 88: 382-389; 1993. doi:10.1111/j.1399-3054.1993.tb05513.x.

Faivre-Rampant O.; Charpantier J.-P.; Kevers C.; Dommes J.; Van Onckelen H.; Jay-Allemand C.; Gaspar T. Cuttings of the nonrooting rac tobacco mutant overaccumulate phenolic compounds. Funct Plant Biol. 29: 63-71; 2002. doi:10.1071/PP01016.

Gaspar T.; Kevers C.; Hausman J. F.; Ripetti V. Peroxidase activity and endogenous free auxin during adventitious root formation. In: Lumdsen, P.J.; Nicholas, J.R.; Davies, W. J. eds. Physiology, growth and development of plants in culture. Kluwer Academic, Dordrecht, pp 289-298; 1994.

Gatineau F.; Fouché J. G.; Kevers C.; Hausman J. J.; Gaspar T. Quantitative variations of indolyl compounds including IAA, IAA-aspartate and serotonin in walnut microcuttings during rooting induction. Biol Plant 391: 131-137; 1997. doi:10.1023/ A:1000377511120.
Gonçalves J. C.; Diogo G.; Amâncio S. In vitro propagation of chestnut (Castanea sativa x $C$. crenata): Effects of rooting treatments on plant survival, peroxidase activity and anatomical changes during adventitious root formation. Sci Hortic. 72: 265275; 1998. doi:10.1016/S0304-4238(97)00136-2.

Hand P. Biochemical and molecular markers of cellular competence for adventitious rooting. In: Davies, T. D.; Haissig, B. E. eds. Biology of adventitious root formation. Plenum, New York, pp 111-121; 1994.

Hausman J. F. Changes in peroxidase activity, auxin level and ethylene production during root formation by poplar shoots raised in vitro. Plant Growth Regul. 13: 262-268; 1993. doi:10.1007/BF00024847.

Heloir M.-C.; Kevers C.; Hausman J.-F.; Gaspar T. Changes in the concentrations of auxins and polyamines during rooting of invitro-propagated walnut shoots. Tree Physiol. 16: 515-519; 1996.

Jarvis B. C. Endogenous control of adventitious rooting in non-woody cuttings. In: Jackson M. B. (ed) New root formation in plants and cuttings. Martinus Nijhoff, Dordrecht, pp 191-222; 1986.

Label P. H.; Sotta B.; Miginiac E. Endogenous levels of abscisic acid and indole-3-acetic acid during in vitro rooting of wild cherry explants produced by micropropagation. Plant Growth Regul. 8: 325-333; 1989. doi:10.1007/BF00024663.

Moncousin C. Rooting in vitro cuttings. In: Bajaj Y. P. S. (ed) Biotechnology in agriculture and forestry, 17. High-tech and micropropagation. Springer, Berlin, pp 213-261; 1991.

Moncousin C.; Favre J. M.; Gaspar T. Changes in peroxidase activity and endogenous IAA levels during adventitious root formation in vine cuttings. In: Kutacek, M.; Bandurski, R. S.; Krekule, J. eds. Physiology and biochemistry of auxins in plants. Academia, Praha, pp 331-337; 1988.

Murashige T.; Skoog F. A revised medium for rapid growth and bioassays with tobacco cultures. Physiol Plant. 15: 473-497; 1962. doi:10.1111/j.1399-3054.1962.tb08052.x.

Nag S.; Saha K.; Choudhuri M. A. Role of auxins and polyamins in adventitious root formation in relation to changes in compounds involved in rooting. J Plant Growth Regul. 20: 182-194; 2001. doi:10.1007/s003440010016.

Nordström A. C.; Eliasson L. Levels of endogenous indole-3-acetic acid and indole-3-acetylaspartic acid during adventitious root formation in pea cuttings. Physiol Plant. 82: 599-605; 1991. doi:10.1111/j.1399-3054.1991.tb02953.x.

Nordström A.-C.; Jacobs F. A.; Eliasson L. Effect of exogenous indole-3-acetic acid and indole-3-butyric acid on internal levels of the respective auxins and their conjugation with aspartic acid during adventitious root formation in pea cuttings. Plant Physiol. 96: 856-861; 1991.

Riov J. Endogenous and exogenous auxin conjugates in rooting of cuttings. Acta Hortic. 329: 264-288; 1993.

Ripetti V.; Kevers C.; Gaspar T. Two successive media for rooting of walnut shoots in vitro. Changes in peroxidase activity and ethylene production. Adv Hortic Sci. 8: 29-32; 1994.

San-José M. C.; Vidal N.; Ballester A. Anatomical and biochemical changes during root formation in oak and apple shoots cultured in vitro. Agronomie 12: 767-774; 1992. doi:10.1051/agro: 19921004.

Stefancic M.; Stampar F.; Veberic R.; Osterc G. The levels of IAA, IAAsp and some phenolics in cherry rootstock 'GiSel 5' leafy cuttings pretreated with IAA and IBA. Sci Hort 112: 399-405; 2007. doi:10.1016/j.scienta.2007.01.004.

van der Krieken W. M.; Breteler H.; Visser M. H. M. The effect of conversion of indolbutyric acid into indolacetic acid on root formation on microcuttings of Malus. Plant Cell Physiol. 33: 709-713; 1992.

Vatulescu A. D.; Fortunato A. S.; Sá M. C.; Amâncio S.; Ricardo C. P. P.; Jackson P. A. Cloning and characterisation of a basic IAA 
oxidase associated with root induction in Vitis vinifera. Plant Physiol Bioch 42: 609-615; 2004. doi:10.1016/j.plaphy.2004. 06.009 .

Vieitez A. M.; Vieitez M. L.; Vieitez E. Chestnut (Castanea spp.). In: Bajaj Y. P. S. (ed) Biotechnology in Agriculture and Forestry. Springer, Berlin, pp 393-414; 1986.
Vieten A.; Sauer M.; Brewer P. B.; Friml J. Molecular and cellular aspects of auxin-transport-mediated development.. Trends in Plant Science 124: 160-168; 2007. doi:10.1016/j.tplants.2007. 03.006 .

Woodward A. W.; Bartel B. Auxin: regulation, action, and interaction. Annals of Botany 95: 707-735; 2005. doi:10.1093/aob/mci083. 